\title{
PERENCANAAN DAN PENGENDALIAN PRODUKSI KANTONGAN PLASTIK MEREK NO.1 PADA PT. DUTA PLASTIK INDUSTRI
}

\author{
${ }^{1}$ Indira Ruth Septarini ${ }^{\bowtie},{ }^{2}$ Christopher \\ ${ }^{1}$ Teknik Industri, Universitas Prima Indonesia, Medan, Indonesia \\ ${ }^{2}$ Teknik Manajemen Industri, Institut Sains \& Teknologi TD. Pardede, Medan, Indonesia \\ Email: indiradamanik@gmail.com
}

DOI: https://doi.org/10.46880/methoda.Vol11No2.pp127-132

\begin{abstract}
Consumer demand for plastic bags to PT. Duta Plastic Industries often run out of stock. PT. Duta Plastic Industries in order to maintain consumer trust always maintain product availability and product quality in good condition. This study focuses on the problem of product inventory ordered by consumers. This study applies the exponential method to predict the amount of plastic production needs to meet customer demand. The results obtained from the research, among others, the number of forecasting the average demand for plastic bags brand No.1 at PT. Duta Plastic Industry in the period January 2018 to December 2018 is size 15 is 43.44 tons/month, size 19 is 37.36 tons/month, and size 24 is 25.43 tons/month. The average amount of raw material inventory per month that must be provided to meet the demand for sales of No.1 brand plastic bags during the period January 2018 to December 2018 which consists of three sizes is 115 tons/month.
\end{abstract}

Keyword: Production, Forecasting, Demand, Scheduling.

\begin{abstract}
ABSTRAK
Permintaan konsumen akan kantong plastik terhadap PT. Duta Plastik Industri seringkali mengalami kehabisan persediaan. PT. Duta Plastik Industri demi menjaga kepercayaan konsumen selalu menjaga ketersediaan produk dan kualitas produk dalam keadaan baik. Penelitian ini fokus pada permasalahan persediaan produk yang dipesan konsumen. Penelitian ini menerapkan metode eksponential untuk meramalkan jumlah kebutuhan produksi plastik guna memenuhi permintaan pelanggan. Hasil yang didapatkan dari penelitian antara lain, jumlah peramalan permintaan rata-rata terhadap kantongan plastik merek No.1 di PT. Duta Plastik Industri pada periode Januari 2018 hingga Desember 2018 adalah ukuran 15 adalah 43,44 ton/bulan, ukuran 19 adalah 37,36 ton/bulan, dan ukuran 24 adalah 25,43 ton/bulan. Jumlah persediaan bahan baku rata-rata per bulan yang harus disediakan untuk memenuhi permintaan penjualan kantongan plastik merek No.1 selama periode Januari 2018 s/d Desember 2018 yang terdiri dari tiga ukuran adalah 115 ton/bulan.
\end{abstract} Kata Kunci: Produksi, Peramalan, Permintaan, Penjadwalan.

\section{PENDAHULUAN}

Faktor Perusahaan pada umumnya melakukan perencanaan dan pengendalian tidak berdasarkan metode-metode yang sudah baku, tetapi hanya berdasarkan pada pengalamanpengalaman sebelumnya. Hal tersebut sering menyebabkan terjadinya kelebihan atau penumpukan bahan baku maupun kekurangannya yang menyebabkan biaya semakin tinggi, disamping terjadi kekurangan yang dapat mengganggu atau menghambat proses produksi dalam memenuhi permintaan konsumen.

PT. Duta Plastik Industri merupakan sebuah perusahaan keluarga yang bergerak dalam bidang perplastikan dan sebagian hasil 
produksinya telah dikirim keluar kota Medan. Produk utama PT. Duta Plastik Industri adalah kantongan plastik bening merek No.1. Melihat proses produksinya yang cepat maka diperlukan persediaan bahan baku yang sesuai guna mengurangi biaya yang tinggi akibat kurangnya atau lebihnya persediaan bahan baku. Pengendalian bahan baku produksi kanton plastik merek No.1 menjadi masalah utama PT. Duta Plastik Industri.

\section{BAHAN DAN METODE}

Penelitian ini dilaksanakan dari bulan Mei sampai dengan bulan Juli 2018 dan bertempat di PT. Duta Plastik Industri yang berlokasi pada Kawasan Industri Binjai di Jl. Pelita III No. 5 KM 12,5 Medan - Binjai, seperti ditunjukkan pada Gambar 1.

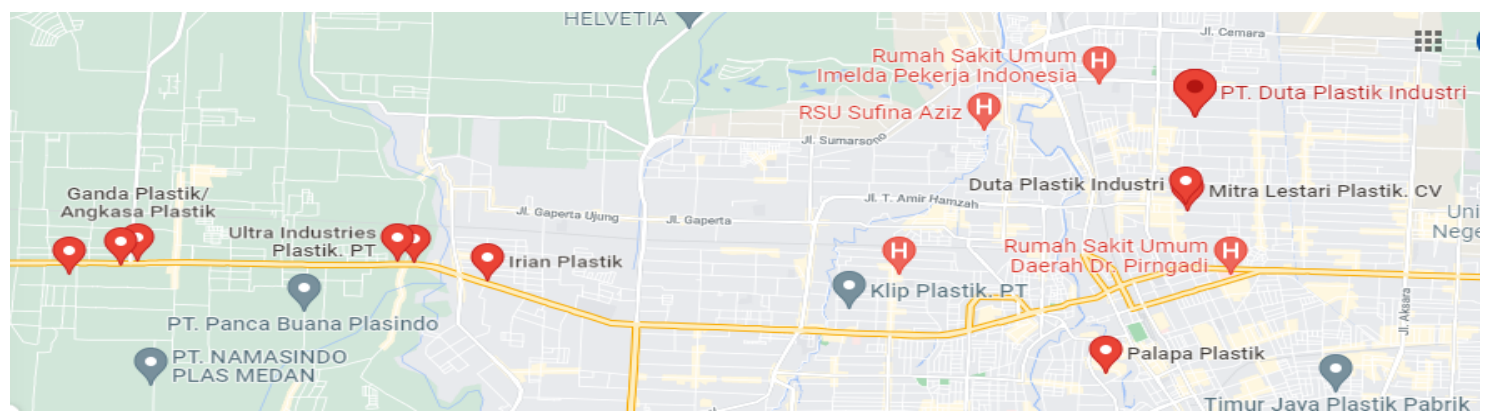

Gambar 1. Lokasi Penelitian

Metode yang digunakan dalam penelitian perencanaan dan pengendalian produksi kantong plastik Merek No.1 PT. Duta Plastik Industri, seperti ditunjukkan pada Gambar 2. Penelitian dimulai dari pengumpulan data, pengolahan data, proses perhitungan peramalan, kebutuhan bahan baku hingga menghitung biaya persediaan bahan baku.

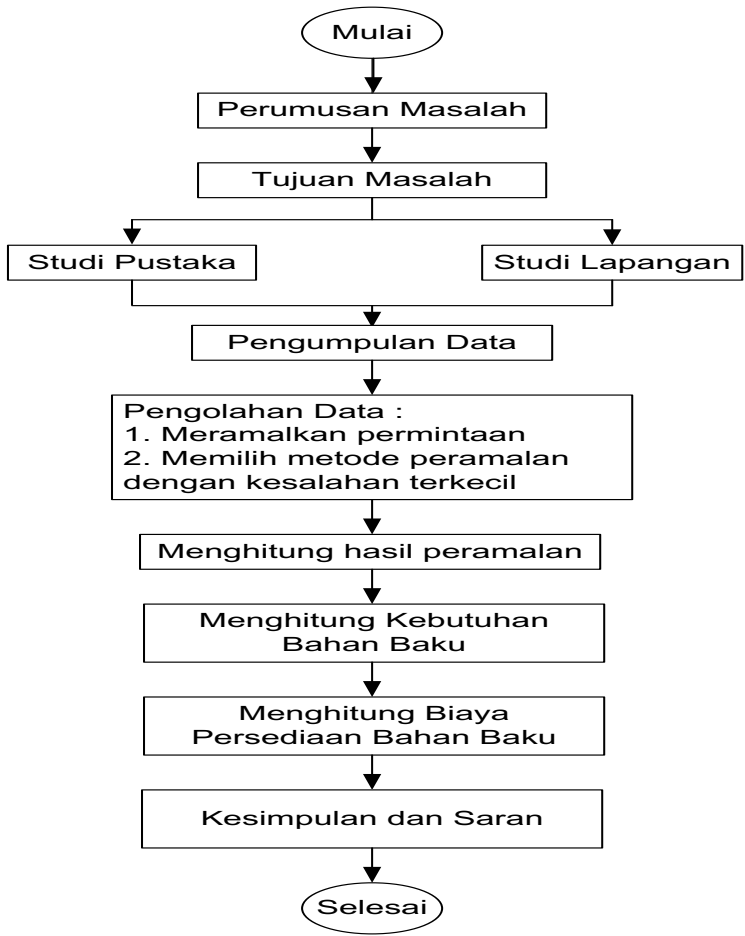

Gambar 2. Metode Penelitian
Data permintaan plastik merek No.1 pada tahun 2017 dengan 3 (tiga) tipe ukuran antara lain ukuran 15, ukuran 19 dan ukuran 24 di PT. Duta Plastik Industri Medan, seperti ditunjukkan pada Tabel 1.

Tabel 1. Permintaan Plastik Merek No.1

\begin{tabular}{|c|c|c|c|c|}
\hline Waktu & Bulan & \multicolumn{3}{|c|}{ Permintaan (Satuan Ton) } \\
\hline & & $\begin{array}{c}\text { Ukuran } \\
\mathbf{1 5}\end{array}$ & $\begin{array}{c}\text { Ukuran } \\
\mathbf{1 9}\end{array}$ & $\begin{array}{c}\text { Ukuran } \\
\mathbf{2 4}\end{array}$ \\
\hline 1 & Januari & 35,00 & 30,0 & 20,0 \\
\hline 2 & Februari & 38,50 & 33,0 & 22,0 \\
\hline 3 & Maret & 52,50 & 45,0 & 30,0 \\
\hline 4 & April & 31,50 & 27,0 & 18,0 \\
\hline 5 & Mei & 33,25 & 28,5 & 19,0 \\
\hline 6 & Juni & 39,55 & 33,9 & 22,6 \\
\hline 7 & Juli & 40,25 & 34,5 & 23,0 \\
\hline 8 & Agustus & 40,95 & 35,1 & 23,4 \\
\hline 9 & September & 42,00 & 36,0 & 24,0 \\
\hline 10 & Oktober & 52,50 & 45,0 & 30,0 \\
\hline 11 & November & 49,00 & 42,0 & 28,0 \\
\hline 12 & Desember & 63,00 & 54,0 & 36,0 \\
\hline Jumlah & & 518 & 444 & 296 \\
\hline
\end{tabular}

\section{HASIL DAN PEMBAHASAN}

Penelitian mencari mencari metode peramalan terbaik untuk menentukan peramalan permintaan produksi plastik yang akan datang. Metode peramalan yang digunakan adalah metode MSE yang terkecil yaitu metode peramalan Exponential. Hasil peramalan 
permintaan dengan menggunakan metode Ukuran 15, Ukuran 19 dan Ukuran 24, seperti exponential untuk plastik Merek No.1 untuk ditunjukkan pada Tabel. 2, Tabel. 3 dan Tabel. 4

Tabel 2. Trend Exponential Plastik Merek No. 1 Ukuran 15

\begin{tabular}{|c|c|c|c|c|c|}
\hline Waktu & $\mathbf{y i}$ & $\mathbf{t i}$ & $\mathbf{y}$ Exponensial & e Exponensial & $\mathbf{e}^{\mathbf{2}}$ Exponensial \\
\hline 1 & 35,00 & -11 & 43,54 & $-8,54$ & 72,9 \\
\hline 2 & 38,50 & -9 & 43,49 & $-4,99$ & 24,9 \\
\hline 3 & 52,50 & -7 & 43,45 & 9,05 & 81,9 \\
\hline 4 & 31,50 & -5 & 43,40 & $-11,90$ & 141,6 \\
\hline 5 & 33,25 & -3 & 43,36 & $-10,11$ & 102,2 \\
\hline 6 & 39,55 & -1 & 43,32 & $-3,77$ & 14,2 \\
\hline 7 & 40,25 & 1 & 43,28 & $-3,03$ & 9,2 \\
\hline 8 & 40,95 & 3 & 43,24 & $-2,29$ & 5,2 \\
\hline 9 & 42,0 & 5 & 43,20 & $-1,20$ & 1,4 \\
\hline 10 & 52,50 & 7 & 43,17 & 9,33 & 87,0 \\
\hline 11 & 49,00 & 9 & 43,14 & 5,86 & 34,3 \\
\hline 12 & 63,00 & 11 & 43,10 & 19,90 & 396,0 \\
\hline$\sum$ & 518 & - & 519,69 & $-1,69$ & 970,8 \\
\hline
\end{tabular}

Tabel 3. Trend Exponential Plastik Merek No. 1 Ukuran 19

\begin{tabular}{|c|c|c|c|c|c|}
\hline Waktu & yi & $\mathbf{t i}$ & y Exponensial & e Exponensial & $\mathbf{e}^{2}$ Exponensial \\
\hline 1 & 30,0 & -11 & 37,46 & $-7,46$ & 55,6516 \\
\hline 2 & 33,0 & -9 & 37,41 & $-4,41$ & 19,4481 \\
\hline 3 & 45,0 & -7 & 37,37 & 7,63 & 58,2169 \\
\hline 4 & 27,0 & -5 & 37,33 & $-10,33$ & 106,7089 \\
\hline 5 & 28,5 & -3 & 37,29 & $-8,79$ & 77,2641 \\
\hline 6 & 33,9 & -1 & 37,25 & $-3,35$ & 11,2225 \\
\hline 7 & 34,5 & 1 & 37,21 & $-2,71$ & 7,3441 \\
\hline 8 & 35,1 & 3 & 37,18 & $-2,08$ & 4,3264 \\
\hline 9 & 36,0 & 5 & 37,14 & $-1,14$ & 1,2996 \\
\hline 10 & 45,0 & 7 & 37,11 & 7,89 & 62,2521 \\
\hline 11 & 42,0 & 9 & 37,07 & 4,93 & 24,3049 \\
\hline 12 & 54,0 & 11 & 37,04 & 16,96 & 287,6416 \\
\hline$\sum$ & 444 & - & 446,86 & $-2,86$ & 715,6808 \\
\hline
\end{tabular}

Tabel 4. Trend Exponential Plastik Merek No. 1 Ukuran 19

\begin{tabular}{|c|c|c|c|c|c|}
\hline Waktu & $\mathbf{y i}$ & $\mathbf{t i}$ & $\mathbf{y}$ Exponensial & e Exponensial & $\mathbf{e}^{\mathbf{2}}$ Exponensial \\
\hline 1 & 20,0 & -11 & 25,52 & $-5,52$ & 30,4704 \\
\hline 2 & 22,0 & -9 & 25,47 & $-3,47$ & 12,0409 \\
\hline 3 & 30,0 & -7 & 25,43 & 4,57 & 20,8849 \\
\hline 4 & 18,0 & -5 & 25,39 & $-7,39$ & 54,6121 \\
\hline 5 & 19,0 & -3 & 25,35 & $-6,35$ & 40,3225 \\
\hline 6 & 22,6 & -1 & 25,31 & $-2,71$ & 7,3441 \\
\hline 7 & 23,0 & 1 & 25,27 & $-2,27$ & 5,1526 \\
\hline 8 & 23,4 & 3 & 25,23 & $-1,83$ & 3,3489 \\
\hline 9 & 24,0 & 5 & 25,19 & $-1,19$ & 1,4161 \\
\hline 10 & 30,0 & 7 & 25,17 & 4,83 & 23,3289 \\
\hline
\end{tabular}




\begin{tabular}{|c|c|c|c|c|c|}
\hline 11 & 28,0 & 9 & 25,13 & 2,87 & 8,2369 \\
\hline 12 & 36,0 & 11 & 25,10 & 10,90 & 118,8100 \\
\hline$\sum$ & 296 & - & 303,56 & $-7,56$ & 325,9683 \\
\hline
\end{tabular}

Hasil peramalan dari permintaan Plastik Merek No.1 PT. Duta Plastik Industri Medan untuk ukuran 15, seperti ditunjukkan pada Tabel 5.

Tabel 5. Peramalan Permintaan Plastik Merek No.1 ukuran 15

\begin{tabular}{|c|c|c|c|}
\hline Waktu & Bulan & $\begin{array}{c}\text { Permintaan } \\
\text { (Satuan Ton) }\end{array}$ & $\begin{array}{c}\text { Peramalan } \\
\text { Permintaan } \\
\text { (Satuan Ton) }\end{array}$ \\
\hline 1 & Januari & 35,00 & 43,32 \\
\hline 2 & Februari & 38,50 & 43,34 \\
\hline 3 & Maret & 52,50 & 43,36 \\
\hline 4 & April & 31,50 & 43,38 \\
\hline 5 & Mei & 33,25 & 43,40 \\
\hline 6 & Juni & 39,55 & 43,43 \\
\hline 7 & Juli & 40,25 & 43,45 \\
\hline 8 & Agustus & 40,95 & 43,47 \\
\hline 9 & September & 42,00 & 43,50 \\
\hline 10 & Oktober & 52,50 & 43,52 \\
\hline 11 & November & 49,00 & 43,54 \\
\hline 12 & Desember & 63,00 & 43,57 \\
\hline Jumlah & & 518 & 444 \\
\hline
\end{tabular}

Hasil peramalan dari permintaan Plastik Merek No.1 PT. Duta Plastik Industri Medan untuk ukuran 19, seperti ditunjukkan pada Tabel 6.

Tabel 6. Peramalan Permintaan Plastik Merek No.1 ukuran 19

\begin{tabular}{|c|c|c|c|}
\hline Waktu & Bulan & $\begin{array}{c}\text { Permintaan } \\
\text { (Satuan Ton) }\end{array}$ & $\begin{array}{c}\text { Peramalan Permintaan } \\
\text { (Satuan Ton) }\end{array}$ \\
\hline 1 & Januari & 30,0 & 37,25 \\
\hline 2 & Februari & 33,0 & 37,27 \\
\hline 3 & Maret & 45,0 & 37,29 \\
\hline 4 & April & 27,0 & 37,31 \\
\hline 5 & Mei & 28,5 & 37,33 \\
\hline 6 & Juni & 33,9 & 37,35 \\
\hline 7 & Juli & 34,5 & 37,37 \\
\hline 8 & Agustus & 35,1 & 37,39 \\
\hline 9 & September & 36,0 & 37,41 \\
\hline 10 & Oktober & 45,0 & 37,44 \\
\hline 11 & November & 42,0 & 37,46 \\
\hline 12 & Desember & 54,0 & 37,48 \\
\hline Jumlah & & & 448,35 \\
\hline
\end{tabular}


Hasil peramalan dari permintaan Plastik Merek No.1 PT. Duta Plastik Industri Medan untuk ukuran 24, seperti ditunjukkan pada Tabel 7.

Tabel 7. Peramalan Permintaan Plastik Merek No.1 ukuran 24

\begin{tabular}{|c|c|c|c|}
\hline Waktu & Bulan & $\begin{array}{c}\text { Permintaan } \\
\text { (Satuan Ton) }\end{array}$ & $\begin{array}{c}\text { Peramalan Permintaan } \\
\text { (Satuan Ton) }\end{array}$ \\
\hline 1 & Januari & 20,0 & 25,31 \\
\hline 2 & Februari & 22,0 & 25,33 \\
\hline 3 & Maret & 30,0 & 25,36 \\
\hline 4 & April & 18,0 & 25,38 \\
\hline 5 & Mei & 19,0 & 25,39 \\
\hline 6 & Juni & 22,6 & 25,42 \\
\hline 7 & Juli & 23,0 & 25,44 \\
\hline 8 & Agustus & 23,4 & 25,46 \\
\hline 9 & September & 24,0 & 25,48 \\
\hline 10 & Oktober & 30,0 & 25,50 \\
\hline 11 & November & 28,0 & 25,53 \\
\hline 12 & Desember & 36,0 & 25,55 \\
\hline Jumlah & & & 305,15 \\
\hline
\end{tabular}

Pada rencana peramalan produksi ini dapat dihitung untuk biaya produksi yang terjadi pada PT. Duta Plastik Industri dalam satu tahun periode Januari 2018 s/d Desember 2018 yaitu:

\begin{tabular}{|c|c|c|c|c|}
\hline - & \multicolumn{4}{|l|}{ Biaya Pemesanan } \\
\hline ○ & \multicolumn{3}{|l|}{ Biaya Persiapan } & Rp. 40.000,- \\
\hline o & \multicolumn{3}{|l|}{ Biaya Pengiriman } & Rp. 200.000,- \\
\hline ० & \multicolumn{3}{|c|}{ Biaya Penyelesaiaan Pembayaran } & Rp. 30.000,- \\
\hline & Total & & & : Rp. 27 \\
\hline- & Biaya Penyimpanan & & & \\
\hline ○ & Biaya Sewa Gudang & & Rp. - & \\
\hline o & Biaya Pemeliharaan (5\%) & & & Rp. 36.750,- \\
\hline o & Pajak dan asuransi $\quad(2 \%)$ & & & Rp. 63.932,- \\
\hline 0 & Biaya penanganan bahan & $(6 \%)$ & & Rp. 525.000,- \\
\hline o & Biaya kerusakan & $(3 \%)$ & & Rp. $85.235,-$ \\
\hline
\end{tabular}

\section{Total}

Biaya Pemesanan / Tahun

Biaya Penyimpanan / Tahun

Total Biaya Persediaan / Tahun

\section{KESIMPULAN}

Berdasarkan penelitian perencaan dan pengendalian produksi kantongan plastik Merek No.1 pada PT. Duta Plastik Industri:

1. Jumlah peramalan permintaan rata-rata terhadap produksi kantongan plastik di PT. Duta Plastik Industri periode Januari 2018 s/d
: Rp. 710.917,-/minggu

:Rp. 12.960.000,-

:Rp. 34.124.016

: Rp. 47.084.016 
c. Rata-rata Kantongan Plastik Merek No.1 ukuran 24 adalah 25 ton/bulan

2. Jumlah persediaan bahan baku rata-rata per bulan yang harus disediakan untuk memenuhi permintaan penjualan Kantongan Plastik Merek No.1 selama periode Januari 2018 s/d Desember 2018 untuk ketiga ukuran rata-rata Kantongan Plastik Merek No.1 ukuran 15,19, dan 24 ialah 115 ton/bulan

3. Perhitungan biaya persediaan yang dikeluarkan dalam periode satu tahun produksi dari periode Januari $2018 \mathrm{~s} / \mathrm{d}$ Desember 2018 adalah sebesar Rp. 47.084.016

\section{DAFTAR PUSTAKA}

Assauri, S. (2010). Manajemen Produksi. Jakarta: Lembaga Penerbit FE-UI.

Fachrurrozi, I. A. (2010). Lot Sizing Material Requirement Planning Pada Produk Tipe Wall Mounting di industri Box Panel. Jakarta: Universitas Mercu Buana.

Herjanto, E. (2003). Manajemen Produksi dan Operasi. Jakarta: PT. Gramedia.

Lundy, M., \& Setyorini, R. (2012).

Perencanaan Kebutuhan Bahan Baku Produk Windlass dengan Menggunakan Metode Lot Sizing pada PT. PINDAD (Persero). Bandung: Universitas Telkom.

Render, B. \& Heizer, J. (2001). Prinsip-prinsip Manajemen Operasi. Jakarta: Salemba Empat.

Handoko, T. H. (2001). Dasar-Dasar Manajemen Produksi dan Operasi (Edisi Pertama). Yogyakarta: Universitas Gajah Mada. 